\title{
Patient and Physician Preferences for Treating Adjuvant Melanoma: A Discrete Choice Experiment
}

\section{Kathleen Beusterien ${ }^{*}$, Mark R. Middleton ${ }^{2}$, Peter Feng Wang ${ }^{3}$, Sumati Rao ${ }^{3}$, Srividya Kotapati ${ }^{3}$, Javier Sabater ${ }^{3}$, Baiju Aurora ${ }^{4}$, John F. P. Bridges ${ }^{5}$}

${ }^{1}$ ORS Health, Washington DC, USA

${ }^{2}$ Department of Oncology, University of Oxford, Churchill Hospital, Oxford, UK

${ }^{3}$ Bristol-Myers Squibb, Princeton, NJ, USA

${ }^{4}$ Aurora Capital, West Orange, NJ, USA

${ }^{5}$ Johns Hopkins Bloomberg School of Public Health, Baltimore, MD, USA

Email: *Kathy.beusterien@orshealth.com

How to cite this paper: Beusterien, K., Middleton, M.R., Wang, P.F., Rao, S., Kotapati, S., Sabater, J., Aurora, B. and Bridges, J.F.P. (2017) Patient and Physician Preferences for Treating Adjuvant Melanoma: A Discrete Choice Experiment. Journal of Cancer Therapy, 8, 37-50.

http://dx.doi.org/10.4236/jct.2017.81004

Received: December 15, 2016

Accepted: January 16, 2017

Published: January 19, 2017

Copyright $\odot 2017$ by authors and Scientific Research Publishing Inc. This work is licensed under the Creative Commons Attribution International License (CC BY 4.0).

http://creativecommons.org/licenses/by/4.0/

\begin{abstract}
Objective: To evaluate and compare patient and physician preferences for the benefits and risks of currently available adjuvant melanoma treatments. Methods: Patients with stage II/III melanoma and oncologists in the USA were recruited from 6 clinical sites and an online panel to complete a survey. Preferences were assessed using a paired comparison discrete choice experiment that allowed for opt-out (i.e. no treatment). The treatments comprised 7 attributes, each with 3 levels associated with pegylated interferon, high-dose interferon, and ipilimumab. Attributes included efficacy outcomes, dosing regimen, and risks of moderate to severe toxicities. In addition, open-ended maximum acceptable risk (MAR) questions assessed tradeoffs between toxicity risk and efficacy. Results: 142 patients (45 stage II; 97 stage III) chose a treatment in $78 \%$ of the choice tasks, while physicians $(N=127)$ chose treatment $79 \%$ of the time. The rankings of relative attribute importance were concordant between the patients and physicians for the top 4: 10-year survival in metastatic melanoma, fatigue risk, 3-year recurrence-free survival (RFS), and depression risk. Patients and physicians valued the difference in $21 \%$ survival versus no survival benefit about 3 and 4 times as much, respectively, as reducing diarrhea risk from $41 \%$ to $1 \%$ or reducing depression risk from $40 \%$ to $1 \%$. The MAR of severe diarrhea and of a life-threatening event increased as the chance of 3-year RFS increased, with patients reporting higher risks than physicians. Conclusion: Patients and physicians were concordant in their preferences in adjuvant melanoma, preferring treatment versus none and judging potential efficacy to outweigh risks of toxicities.
\end{abstract}

\section{Keywords}

Melanoma, Adjuvant Therapy, Discrete Choice Experiment 


\section{Introduction}

Melanoma is an aggressive type of skin cancer that refers to a malignant tumor of melanocytes, the melanin-producing cells found mostly in the skin [1]. In the USA, the American Cancer Society estimates that there will be approximately 76,380 new melanomas diagnosed in 2016, with around 46,870 in men and 29,510 in women. The median age at diagnosis of melanoma is 62 years, and $55.4 \%$ of patients are under aged 65 years at diagnosis [2]. When melanoma is found early, it can often be cured by surgery; after it spreads, however, it is more difficult to treat. In stage III melanoma, the cancer is present not only in the skin, but also in the lymph nodes. Stage III melanoma is described in 3 categories: $a, b$, and c. The estimated 5-year survival rates for these categories are $78 \%, 59 \%$, and $40 \%$, respectively [3].

Surgery is the first-line treatment for patients with intermediate thickness melanoma. After surgery, other treatments may be considered, including low-dose pegylated-interferon (peg-IFN) and high-dose IFN $\alpha 2 b$ (HDI) [4] [5]. More recently, the anti-cytotoxic T-lymphocyte antigen 4 (CTLA-4) antibody, ipilimumab, has been investigated in phase 3 trials and approved by the US Food and Drug Administration (FDA) in October 2015 [6]. Given that these 3 adjuvant melanoma treatments differ in levels of toxicity and mode/frequency of administration, there is a need for considering trade-offs of benefits and risks when choosing among them. Such comparisons are hindered by the lack of head-to-head comparisons between treatments and uncertainties around relative efficacy. In choosing a treatment approach, there is a role for patients, as well as physicians, as melanoma patients want to play an active role in their treatment decisions [7] [8].

Previous research has demonstrated that melanoma patients are willing to endure toxicities for an improvement in survival [9] [10], yet there is a paucity of evidence focused on the preferences of patients with melanoma or oncologists in the value of particular adjuvant treatments where multiple treatment options exist. Moreover, even if patients are eligible for adjuvant treatment, it is unknown whether or not they prefer to receive treatment at this stage, when there is only a risk of recurrence, or wait until a recurrence occurs. This study evaluated patient and physician preferences for treatment and the trade-offs that both groups are willing to make among key benefits and risks associated with HDI, peg-IFN, and ipilimumab.

\section{Materials and Methods}

Patients with stage II or III melanoma and medical oncologists in the USA were recruited to complete an online survey from October 2015 to February 2016. To ensure geographic diversity, patients were recruited from 6 clinical sites and from an online market research panel in the USA. The oncologists were recruited through an online panel of US physicians. All participants completed an online screener to determine study eligibility. To be eligible to participate, patients had to be at least 18 years of age and reside in the USA, with a current diagnosis of stage II or stage III melanoma for which they had undergone surgery. Patients were permitted to have received adjuvant therapy for melanoma. Physicians were required to be medical oncologists residing in the USA and to have treated or managed $\geq 5$ patients with stage III melanoma in the past 2 years. All patients endorsed an informed consent form, and the study was ap- 
proved by the Magil IRB (Rockville, MD).

\subsection{Survey Development}

A discrete choice experiment (DCE), a common stated preference method endorsed by the FDA [11], was used to elicit preferences for key characteristics (attributes) of HDI, peg-IFN, and ipilimumab [12] [13]. Specifically, a series of choice tasks were shown asking the respondent to choose the most preferred from 2 hypothetical treatments (labeled A and B) or an opt-out (i.e. no treatment). The treatment profiles represented different combinations of attribute levels and varied across questions [14].

The selection of the attributes was based on estimates reported in the literature, including the most frequent toxicities, as well as key treatment concerns identified by 3 oncologists. Seven attributes, each with 3 levels, including efficacy estimates, dosing regimen, and key toxicities, were selected for inclusion, and they were pretested with 3 patients and 3 oncologists. Table 1 presents the attributes and levels included in the survey. Descriptions for the toxicity attributes, which were fatigue, diarrhea, and hypophysitis, were developed to be consistent with the Common Terminology Criteria for

Table 1. DCE attributes and levels.

\begin{tabular}{|c|c|c|c|}
\hline Attribute & Level 1 & Level 2 & Level 3 \\
\hline $\begin{array}{l}\text { Increase in 3-year RFS } \\
\text { Chance of remaining } \\
\text { cancer-free over } 3 \text { years } \\
\text { increases } \mathrm{X} \%\end{array}$ & $4 \%$ & $8 \%$ & $12 \%$ \\
\hline $\begin{array}{l}10 \text {-year survival in } \\
\text { metastatic melanoma }\end{array}$ & $\begin{array}{c}\text { Among metastatic patients (patients } \\
\text { whose cancer has spread), has not } \\
\text { proven to show a survival benefit } \\
\text { over } 10 \text { years }\end{array}$ & $\begin{array}{c}\text { Among metastatic patients (patients } \\
\text { whose cancer has spread), proven to } \\
\text { show that } 10 \% \text { remain alive for at } \\
\text { least } 10 \text { years }\end{array}$ & $\begin{array}{c}\text { Among metastatic patients (patients } \\
\text { whose cancer has spread), proven to } \\
\text { show that } 21 \% \text { remain alive for at } \\
\text { least } 10 \text { years }\end{array}$ \\
\hline Dosing regimen & $\begin{array}{l}\text { IV infusion at clinic } 1 \text { time every } 3 \\
\text { weeks for } 4 \text { times and then } 1 \text { time } \\
\text { every } 3 \text { months for } 3 \text { years }\end{array}$ & $\begin{array}{l}\text { IV infusion at clinic } 5 \text { days a week for } \\
1 \text { month and then self-injection under } \\
\text { the skin } 3 \text { times per week for } 1 \text { year }\end{array}$ & $\begin{array}{l}\text { Self-injection under the skin } 1 \text { time } \\
\text { per week for } 5 \text { years }\end{array}$ \\
\hline $\begin{array}{l}\text { Fatigue risk } \\
\text { Chance of fatigue, not } \\
\text { relieved by rest, limiting } \\
\text { work and daily activities }\end{array}$ & $32 \%$ & $60 \%$ & $95 \%$ \\
\hline $\begin{array}{l}\text { Diarrhea risk } \\
\text { Chance of diarrhea ( }>3 \\
\text { episodes per day), limiting } \\
\text { work and daily activities }\end{array}$ & $1 \%$ & $27 \%$ & $41 \%$ \\
\hline $\begin{array}{c}\text { Depression risk } \\
\text { Chance of depression, with } \\
\text { low mood and lacking } \\
\text { motivation, limiting work } \\
\text { and daily activities }\end{array}$ & $1 \%$ & $40 \%$ & $59 \%$ \\
\hline $\begin{array}{l}\text { Hypophysitis risk } \\
\text { Chance of pituitary gland } \\
\text { inflammation, causing } \\
\text { headaches and requiring } \\
\text { long-term hormone therapy }\end{array}$ & $0 \%$ & $5 \%$ & $18 \%$ \\
\hline
\end{tabular}

Note: $\mathrm{DCE}=$ discrete choice experiment; IV = intravenous; RFS = recurrence-free survival. 
Adverse Events, v4.0 [15], for grade 2 and above. Even though the toxicity attributes were described as moderate to severe toxicity, the risk levels for the toxicities conservatively reflected the overall risk of each toxicity, regardless of grade, based on published ranges for HDI, peg-IFN and ipilimumab among adjuvant melanoma patients [16] [17] [18] [19]. One attribute described 10-year survival in patients with metastatic melanoma, given recent findings reporting survival lasting over 10 years after ipilimumab therapy [20].

The same attributes and levels were used in both patient and physician surveys. In responding to the survey, the physicians were asked to imagine that they were patients [21]. Specifically, they were asked to imagine that they have been diagnosed with stage III melanoma and have had surgery to remove it, but there still is a high risk of disease recurrence.

The experimental design of the DCE was a balanced design with minimal overlap [22]. The design was generated to optimize overall design efficiency in terms of (a) level balance (each level is shown approximately an equal number of times); (b) minimal level overlap (levels repeat within same task); and (c) orthogonality (levels may be evaluated independently of other levels). An example choice task is shown in Figure 1. Thirteen tasks based on experimental design plus two fixed choice head-to-head comparison tasks, one of which included profiles based upon ipilimumab and HDI, as well as none (Figure 1 shows the fixed choice task 1; Treatment A reflects the ipilimumab profile and Treatment B reflects the HDI profile), and the second of which included profiles based upon ipilimumab and peg-IFN, as well as none (the profile for peg-IFN

If these were your only options, which would you choose?

Select by placing a mark in the box below the treatment you would choose:

\section{Treatment A}

IV infusion at clinic 1 time very 3 weeks for 4 times and then 1 time every 3 months for 3 years

Chance of remaining cancer-free over 3 years increases $12 \%$

$32 \%$ chance of fatigue, not relieved by rest, limiting work and daily activities

$41 \%$ chance of diarrhea ( $>3$ episodes per day), limiting work and daily activities

$1 \%$ chance of depression, with low mood and lacking motivation, limiting work and daily activities

$18 \%$ chance of pituitary gland inflammation causing headaches and requiring long-term hormone therapy

Among metastatic patients (patients whose cancer las spread), proven to show that approximately $\mathbf{2 1 \%}$ of patients remain alive for at least 10 years

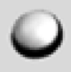

\section{Treatment B}

IV infusion at clinic 5 days a week for 1 month and then self-injection under the skin 3 times per week for 1 year

Chance of remaining cancer-free over 3 years increases $8 \%$

$\mathbf{9 5 \%}$ chance of fatigue, not relieved by rest, limiting work and daily activities

$1 \%$ chance of diarrhea ( $>3$ episodes per day), limiting work and daily activities

None

$\mathbf{4 0} \%$ chance of depression, with low mood and lacking motivation, limiting work and daily activities

$\mathbf{0 \%}$ chance of pituitary gland inflammation, causing headaches and requiring long-term hormone therapy

Among metastatic patients (patients whose cancer has spread), has not proven to show a survival benefit over 10 years

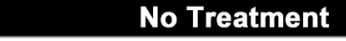

.

\section{No Treatment}


was similar to that of HDI, except peg-IFN had 4\% 3-year efficacy, 27\% diarrhea risk, and 59\% depression risk, and involved self-injection under the skin 1 time per week for 5 years; no treatment names were used in the survey). With the exception of the two fixed tasks, all respondents answered a different set of DCE tasks. To familiarize participants with the attributes in preparation for the DCE, the survey began with questions asking respondents to rate each attribute level on a 5-point Likert scale.

In addition to the DCE, the survey included 6 open-ended maximum acceptable risk (MAR) questions [23]. Three questions asked for the maximum risk of moderate to severe diarrhea (described as $>3$ episodes per day with inflammation of the colon and stomach pain, and requiring steroid treatment) that the respondent is willing to accept for a treatment with different levels of increased chance of being cancer-free over 3 years: $4 \%, 8 \%$, and $12 \%$. The same 3 questions were then again asked referring to a life-threatening side effect.

\subsection{Analysis}

Descriptive statistics, including means and proportions, were used to summarize the data, as applicable. To estimate preference weights for each attribute level, a hierarchical Bayesian (HB) model was fitted to the choice data [24]. The underlying choiceprobability model in $\mathrm{HB}$ was conditional logit, using effects coding for the attribute levels. The results were then used to construct the joint posterior distribution of preference weights over the entire sample, including the mean and standard deviation for each attribute level. The model assumed that the preferences were normally distributed. Preference weights measure relative preference, which means that only changes between attribute-level estimates and the relative size of those changes across attributes have meaningful interpretations [24].

The parameter estimates (utilities) from the $\mathrm{HB}$ analysis enabled the calculation of the conditional relative importance of each attribute. Specifically, the relative importance is calculated at the respondent level by dividing the range of each attribute (utility of highest level minus utility of lowest level) by the sum of ranges of all attributes, and multiplying by 100 . For each respondent, the relative importance estimates across attributes add to $100 \%$. The estimates indicate how much the difference between the best and worst levels of each attribute (e.g. difference between lowest risk versus highest risk of toxicity) affects the decision to choose a treatment. Difference in relative importance estimates were compared among selected groups using analysis of variance tests. SPSS Statistics v22.0 and Sawtooth Software (Orem, UT) were used to conduct the analyses.

\section{Results}

A total of 142 patients and 127 oncologists responded to the survey, and all were included in the analysis. Of the 142 patients, 97 reported having stage III melanoma, 11 stage IIb melanoma, 10 stage IIa melanoma, and 24 reported stage II disease but did not know which sub-stage they had; 44 patients had undergone adjuvant treatment, all with interferon. Table 2 reports the patient and physician demographic characteristics. Among patients, the mean time since melanoma diagnosis was 6.2 years, and the mean time since the most recent surgery was 4.8 years. The patients expected to live a mean 
of 27 additional years, and they perceived that they have an average of $25.3 \%$ likelihood of their cancer returning or worsening over the next 3 years. Most of the physicians (90\%) were currently managing over 5 patients with stage III melanoma. The physicians were mainly in community-based practice ( $76 \%$ of the time); $58 \%$ were a practice owner, partner, or associate (58\%) or were employed by a hospital (31\%).

\subsection{DCE Findings}

Table 3 reports the specific attribute level preference weights for patients and physicians. A survival benefit in the metastatic setting was valued the most among patients and physicians. For patients, a change from no benefit to a $21 \%$ survival benefit [71.0 $(-77.8)=148.8]$ yielded about 3 times the utility as reducing diarrhea risk from $41 \%$ to

Table 2. Demographic characteristics: patients and physicians.

\begin{tabular}{|c|c|c|}
\hline Characteristic & Patients $n=142$ & Physicians $n=127$ \\
\hline Age $($ mean $\pm S D)$ & $57.9 \pm 12.5$ & $50 \pm 9.32$ \\
\hline \multicolumn{3}{|l|}{ Gender, $n(\%)$} \\
\hline Male & $83(58.5)$ & $110(86.6)$ \\
\hline Female & $59(41.5)$ & $17(13.4)$ \\
\hline Total states, $\mathrm{n}$ & 32 & 27 \\
\hline \multicolumn{3}{|l|}{ US location, $n(\%)$} \\
\hline Northeast & $23(16.2)$ & $41(32)$ \\
\hline Midwest & $53(37.3)$ & $32(25)$ \\
\hline Southeast & $29(20.4)$ & $30(24)$ \\
\hline West & $37(26.1)$ & $24(19)$ \\
\hline \multicolumn{3}{|l|}{ Race/ethnicity, n (\%) } \\
\hline White & $120(84.5)$ & $73(57.5)$ \\
\hline Hispanic or Latino & $11(7.7)$ & $4(3.1)$ \\
\hline American Indian or Native American & $3(2.1)$ & $1(0.8)$ \\
\hline Asian, Asian American, or Pacific Islander & $2(1.4)$ & $29(22.8)$ \\
\hline Black or African American & $1(0.7)$ & $1(0.8)$ \\
\hline Multiracial & $1(0.7)$ & $1(0.8)$ \\
\hline Other & $1(0.7)$ & $1(0.8)$ \\
\hline Do not wish to respond & $3(2.1)$ & $17(13.4)$ \\
\hline Have comorbid condition, $n(\%)$ & $104(73.2)$ & $27(22.3)$ \\
\hline \multicolumn{3}{|l|}{ Highest education level attained, $n(\%)$} \\
\hline Elementary school & $1(0.7)$ & \\
\hline High school & $36(25.4)$ & \\
\hline Associates degree & $33(23.2)$ & \\
\hline Bachelor's degree & $39(27.5)$ & \\
\hline Postgraduate degree & $33(23.2)$ & $127(100)$ \\
\hline \multicolumn{3}{|l|}{ Employment (work for pay), $n(\%)$} \\
\hline Yes, full time & $69(48.6)$ & $127(100)$ \\
\hline Yes, part time & $26(18.3)$ & \\
\hline No & $47(33.1)$ & \\
\hline
\end{tabular}


Table 3. Attribute-level preference weights: patients and physicians.

\begin{tabular}{|c|c|c|}
\hline Attribute level & $\begin{array}{c}\text { Patients }(n=142) \\
\text { Mean }(\mathrm{SD})\end{array}$ & $\begin{array}{c}\text { Physicians }(n=127) \\
\text { Mean }(\mathrm{SD})\end{array}$ \\
\hline \multicolumn{3}{|l|}{ Increase in 3-year recurrence-free survival } \\
\hline $4 \%$ & $-43.0(38)$ & $-33.2(43)$ \\
\hline $8 \%$ & $8.9(24)$ & $-2.3(19)$ \\
\hline $12 \%$ & $34.1(35)$ & $35.5(40)$ \\
\hline \multicolumn{3}{|l|}{ 10-year survival benefit in metastatic patients } \\
\hline No proven benefit & $-77.8(67)$ & $-116.4(78)$ \\
\hline $10 \%$ remain alive & $6.8(36)$ & $-4.1(31)$ \\
\hline $21 \%$ remain alive & $71.0(84)$ & $120.5(70)$ \\
\hline \multicolumn{3}{|l|}{ Dosing regimen } \\
\hline Self-injection under skin 1 time per week for 5 years & $-4.50(43)$ & $3.4(25)$ \\
\hline $\begin{array}{l}\text { IV infusion at clinic } 1 \text { time every } 3 \text { week for } 4 \text { times } \\
\text { then } 1 \text { time every } 3 \text { months for } 3 \text { years }\end{array}$ & $15.5(42)$ & $-1.8(28)$ \\
\hline $\begin{array}{l}\text { IV infusion at clinic } 5 \text { days a week for } 1 \text { month then } \\
\text { self-injection under the skin } 3 \text { times per week for } 1 \text { year }\end{array}$ & $-11.0(40)$ & $-1.6(33)$ \\
\hline \multicolumn{3}{|l|}{ Risk of moderate to severe fatigue } \\
\hline $32 \%$ & $45.8(36)$ & $35.4(38)$ \\
\hline $60 \%$ & $12.4(29)$ & $12.5(25)$ \\
\hline $95 \%$ & $-58.2(30)$ & $-47.9(38)$ \\
\hline \multicolumn{3}{|l|}{ Risk of moderate to severe diarrhea } \\
\hline $1 \%$ & $30.1(31)$ & $18.7(32)$ \\
\hline $27 \%$ & $-3.2(22)$ & $0.03(30)$ \\
\hline $41 \%$ & $-26.8(30)$ & $-18.8(37)$ \\
\hline \multicolumn{3}{|l|}{ Risk of moderate to severe depression } \\
\hline $1 \%$ & $39.4(31)$ & $28.7(27)$ \\
\hline $40 \%$ & $-8.2(21)$ & $-10.6(22)$ \\
\hline $59 \%$ & $-31.2(31)$ & $-18.2(33)$ \\
\hline \multicolumn{3}{|l|}{ Risk of hypophysitis } \\
\hline $0 \%$ & $9.1(21)$ & $10.5(26)$ \\
\hline $5 \%$ & $11.2(20)$ & $-1.7(24)$ \\
\hline $18 \%$ & $-20.3(25)$ & $-8.8(32)$ \\
\hline None & $-90.7(294)$ & $-97.2(212)$ \\
\hline
\end{tabular}

Note: Estimated utilities are level-specific and zero-centered and should be interpreted within each attribute (higher utility implies stronger preference); IV = intravenous; $\mathrm{SD}=$ standard deviation.

$1 \%[30.1-(-26.8)=56.9]$ or reducing depression risk from $40 \%$ to $1 \%[39.4-(-8.2)=$ 47.6]. Comparatively, the survival benefit of $21 \%$ versus none [120.5 $-(-116.4)=236.9]$ yielded about 4 times as much utility among physicians. Both patients and physicians valued the improvement from a $4 \%$ to $12 \%$ increase in 3-year recurrence-free survival (RFS) more highly than reducing diarrhea risk from $41 \%$ to $1 \%$, depression risk from $59 \%$ to $1 \%$, and hypophysitis risk from $18 \%$ to $0 \%$. Across all the choice tasks, patients chose a treatment $78 \%$ of the time, and physicians chose a treatment $79 \%$ of the time. 
Figure 2 shows the conditional relative importance estimates for each attribute for patients and physicians. These estimates reflect how much difference each attribute could make in the total utility of a treatment, and they are based on the difference between the worst versus the best level. The rank order of the importance estimates was the same between patients and physicians for the first 4 attributes: 10 -year survival in metastatic melanoma was ranked as most important, followed by the risk of fatigue, 3-year RFS, and risk of depression. Physicians valued the difference between 10 -year survival of $21 \%$ and no proven survival benefit in metastatic melanoma more highly than patients (36\% vs. $27 \%$; $\mathrm{p}<0.001)$. In contrast, compared with physicians, patients valued the difference between $32 \%$ and $95 \%$ risk of fatigue more highly $(17 \%$ and $15 \% ; \mathrm{p}=0.02)$, the difference between a $1 \%$ and $41 \%$ risk of diarrhea more highly $(12 \%$ vs. $10 \%$; $=0.01)$, and the difference among dosing regimens more highly $(12 \%$ vs. $8 \%$; $<<0.001)$.

The relative preferences for the attributes differed significantly between stage III plus IIb patients $(N=108)$ versus stage IIa or stage II subgroup unknown patients $(N=34)$ for 3 attributes. Specifically, compared to stage IIa plus unknown subgroup patients, stage III plus IIb patients valued diarrhea risk more highly ( $12 \%$ vs. $9 \%$; $p=0.031)$, depression risk less $(10 \%$ vs. $14 \%$; $\mathrm{p}=0.031)$, and dosing regimen less $(11 \%$ vs. $14 \%$; $\mathrm{p}=$ 0.030). Differences in relative preferences were observed between patients with previous IFN experience $(N=44)$ versus IFN-naïve patients $(N=98)$. Specifically, compared to IFN-naïve patients, IFN-experienced patients valued chance of 3-year RFS more highly ( $19 \%$ vs. $11 \%$; $\mathrm{p}<0.001)$, survival in metastatic melanoma less $(22 \%$ vs. $29 \%$; $\mathrm{p}=0.003)$, dosing regimen more highly ( $15 \%$ vs. $9 \%$; $\mathrm{p}<0.001)$, fatigue risk less $(15 \%$ vs. $17 \% ; \mathrm{p}=$ 0.028 , and diarrhea risk less ( $9 \%$ vs. $12 \%$; $\mathrm{p}=0.017)$. Examination of the preference weights for dosing regimen among the IFN-experienced patients showed that they most preferred the HDI dosing regimen (8.1), followed by the ipilimumab dosing regimen (6.2) and the peg-IFN dosing regimen (-14.2) (data not tabulated).

Figure 3 shows the percentages of patients and oncologists preferring each option in

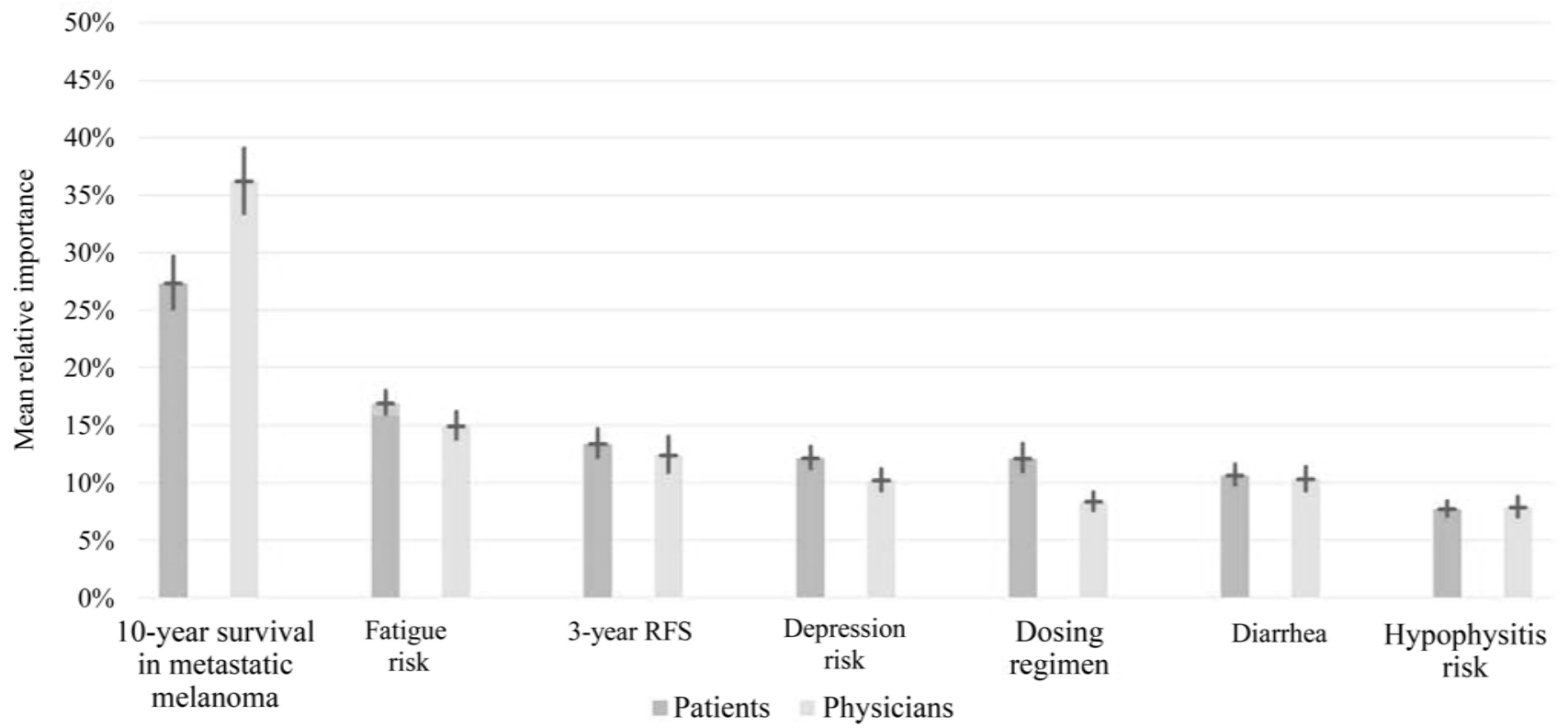

Figure 2. Mean (95\% CI) relative attribute importance: patients and physicians. Note: Attribute importance ranges from $0 \%$ to $100 \%$ and are ratio-scaled: a level with $20 \%$ importance is twice as preferred as one with a $10 \%$ importance. RFS $=$ recurrence-free survival. 


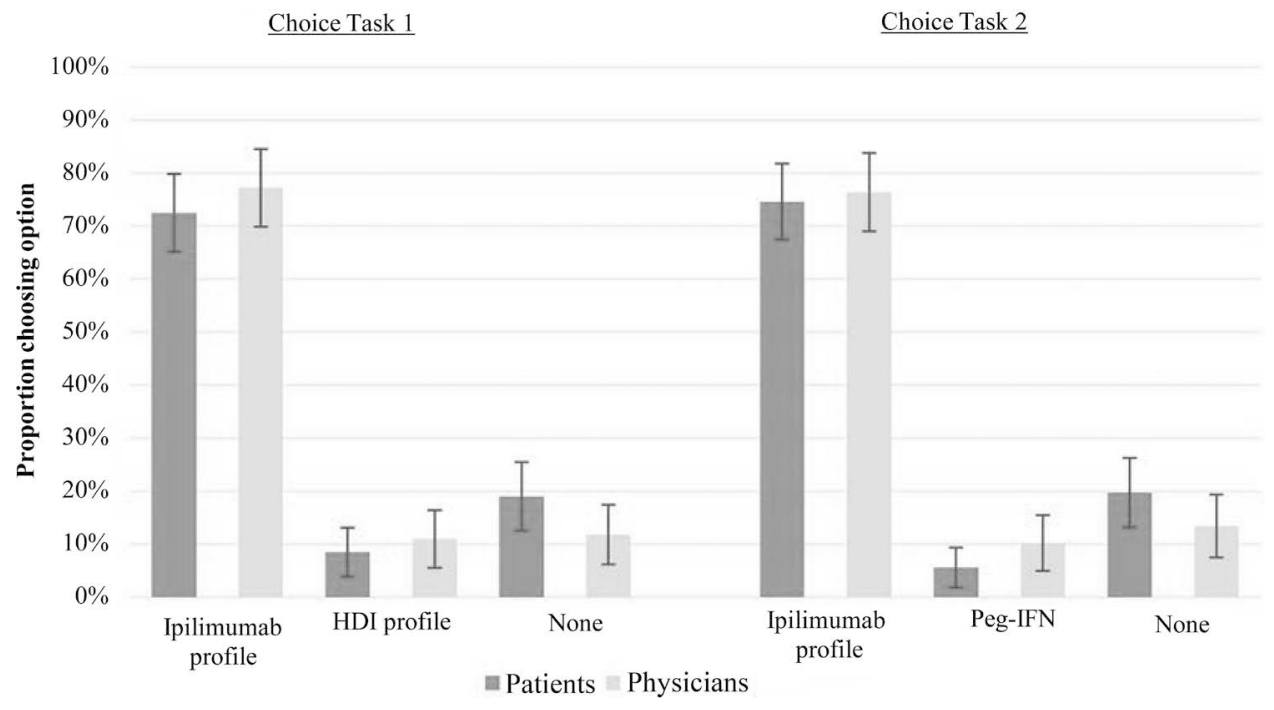

Figure 3. Choice of most preferred treatment in head-to-head comparison tasks. Note: No treatment names were used in survey. 95\% confidence intervals shown.

the head-to-head comparison tasks, which included: a) ipilimumab profile vs. HDI profile vs. none; and b) ipilimumab profile vs. peg-IFN profile vs. none. In the former choice task, patients were 2.6 times more likely to choose ipilimumab; in the latter task, patients were almost 3 times more likely to choose ipilimumab. Among physicians, the odds of choosing ipilimumab profile were 3.3 and 3.2, respectively, for these tasks.

\subsection{Maximum Acceptable Risk}

Figure 4 shows the MAR estimates of moderate to severe diarrhea and of a lifethreatening side effect that patients and physicians, assuming that they had stage III melanoma, reported that they would be willing to take for an increase in the chance of remaining cancer free over 3 years by $6 \%, 12 \%$, and $18 \%$. In both groups, the MAR increased as the chance of 3-year RFS increased. Patients reported a significantly higher mean MAR of moderate to severe diarrhea than physicians to take a treatment that would increase their chance of remaining cancer free by $6 \%(24.8 \%$ vs $19.8 \%$; $p<0.05)$, $12 \%(32.1 \%$ vs $26.6 \% ; \mathrm{p}<0.05)$, and $18 \%(43.7 \%$ vs $31.9 \%$; $<<0.05)$. The mean MAR of a life-threatening event was significantly higher for patients than physicians when the treatment would increase the chance of remaining cancer free by $12 \%$ ( $16.1 \%$ vs $11.9 \%$; $\mathrm{p}<0.05)$ and $18 \%(23.5 \%$ vs $15.2 \%$; $\mathrm{p}<0.05)$.

\section{Discussion}

Using stated preference methodology, this study found that over two-thirds of patients and oncologists preferred treatment versus none in the adjuvant melanoma setting. Adjuvant melanoma treatment preferences were similar between patients and physicians, with both groups placing highest importance on 10-year survival in the metastatic setting, despite it reflecting a more advanced cancer stage than that being considered for the experiment. The second and third attributes that made the most difference in the total utility of a treatment among patients and physicians were the risk of fatigue and 3-year RFS. In response to open-ended MAR questions, both patients and physi- 


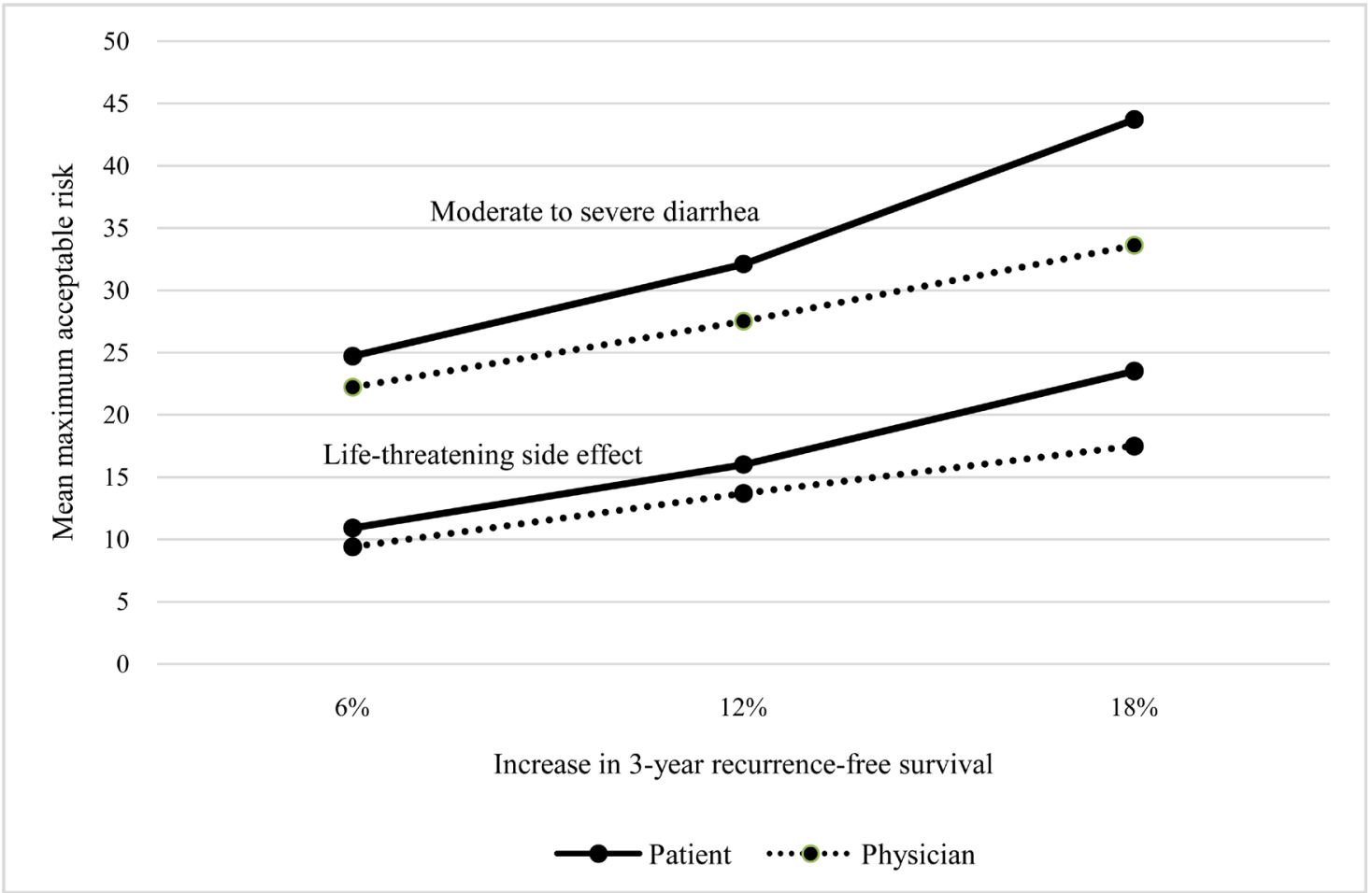

Figure 4. Directly elicited maximum acceptable risks for increase in 3-year recurrence-free survival.

cians indicated that they would accept risks of moderate to severe diarrhea or a life-threatening event in exchange for relatively small increases in the chance of being cancer free in 3 years. The comparability in the findings between patients and physicians is encouraging given that it may help align patient-physician communications in treatment decision-making.

Our finding of the importance of even small improvements in efficacy is consistent with other studies in melanoma that have focused on making trade-offs between potential improvements in survival and increased chances of toxicities. Kilbridge et al found that at least half of low-risk melanoma patients were willing to tolerate mild-moderate and severe IFN toxicity for $4 \%$ and $10 \%$ improvements, respectively, in 5-year disease-free survival [9]. Krammer and Heinzerling found that patients with melanoma in different stages of the disease showed a high willingness to endure side effects despite very small survival gains (down to 1 extra week) or even only hope with no survival benefit [10]. Finally, a review of patient preference studies in breast cancer found that most participants judged small to moderate benefits sufficient to consider adjuvant systemic therapy worthwhile [25].

The higher MAR observed among patients versus physicians is consistent with a previous trade-off study that found that larger percentages of patients were willing to accept treatment toxicities than healthcare professionals for each likelihood of survival to 3 years [26]. The lower importance on fatigue risk among IFN-experienced patients relative to IFN-naïve patients suggests that patients who have had side effects from adjuvant treatment may have acclimated to these effects and are willing to accommodate these in return for higher efficacy. And the finding that IFN-experienced patients most preferred the HDI dosing regimen and least preferred the peg-IFN regimen may be at- 
tributable to the longer treatment duration of the peg-IFN regimen, as patients in the pre-test noted that they favored shorter treatment durations.

A previous study of the clinical use of adjuvant immunotherapy in the USA found that adjuvant immunotherapy use was associated with younger age, higher socioeconomic status, lower comorbidity, facility location, histology, positive nodes, and stage (greater-than or equal to) IIb [27]. The current study contributes information on patient-specific preferences that may be helpful in further informing patient-physician discussions about adjuvant melanoma treatment.

In this study, patients and physicians found the ipilimumab profile to be more favorable than those for HDI and peg-IFN. Given the preference findings, the key drivers for preferring ipilimumab were its favorable effectiveness observed over 10 years among metastatic melanoma patients, lower risk of fatigue, and higher 3-year RFS in the adjuvant setting. Although the ipilimumab treatment profile included a $12 \%$ increase in 3-year RFS, and the HDI profile included an $8 \%$ increase, ipilimumab has not demonstrated superiority compared with IFN in preventing melanoma recurrence in stage III melanoma. The findings did not change in sensitivity analyses assuming equal 3-year RFS among the treatments, but the uncertainty surrounding estimates of efficacy in our profiles represent a significant limitation in our study. Nevertheless, since this study was initiated, new long-term data have been published showing more favorable overall survival for ipilimumab versus placebo among patients with adjuvant melanoma [28]. Such findings lend further support to the efficacy estimates incorporated into the treatment profile matching to ipilimumab in the current study.

The melanoma treatment landscape is changing, particularly with the introduction of nivolumab, pembrolizumab, and new combination treatments, including nivolumab with ipilimumab, demonstrating high efficacy in patients with advanced melanoma. Clinical trials of these agents in the adjuvant setting are planned or ongoing (including KEYNOTE-054 for pembrolizumab and CheckMate 238 for nivolumab plus ipilimumab combination treatments) and will likely result in further changes in the adjuvant landscape. There remains a high unmet medical need as many of patients still fail to respond, reinforcing the need for highly efficacious adjuvant treatment. New clinical trials are needed to understand the optimal treatment pathway for stage III and IV melanoma. Moreover, more data are needed on whether or not the use of drugs in the adjuvant setting limits their efficacy in more advanced disease. Research is ongoing, including the E1609 study comparing adjuvant ipilimumab with HDI, to help address these questions.

\section{Conclusion}

This study found that patients and oncologists preferred treatment for melanoma versus none in the adjuvant setting and expressed a willingness to accept potentially severe treatment-related toxicities in exchange for reducing the chance of disease recurrence. Among key adjuvant melanoma treatment attributes, patients and oncologists placed highest importance on efficacy, even when it has been demonstrated in an advanced stage of disease. The consistency between the patients and oncologists in this study may encourage constructive patient-physician interactions when making decisions about 
adjuvant melanoma treatment.

\section{Acknowledgements}

The authors would like to thank Kaitlan Amos for performing the programming and statistical analysis for this research. Editorial assistance was provided by Stephan Lindsey, PhD, and Cara Hunsberger at StemScientific, an Ashfield Company, funded by Bristol-Myers Squibb.

\section{References}

[1] Garbe, C., Peris, K., Hauschild, A., et al. (2012) Diagnosis and Treatment of Melanoma. European Consensus-Based Interdisciplinary Guideline-Update 2012. European Journal of Cancer, 48, 2375-2390. https://doi.org/10.1016/j.ejca.2012.06.013

[2] American Cancer Society. Key Statistics for Melanoma Skin Cancer. 2016. http://www.cancer.org/cancer/skincancer-melanoma/detailedguide/melanoma-skin-cancer -key-statistics

[3] American Cancer Society. Cancer Facts and Figures 2009. http://www.cancer.org/research/cancerfactsstatistics/cancerfactsfigures2009/

[4] Grob, J.J., Jouary, T., Dréno, B., et al. (2013) Adjuvant Therapy with Pegylated Interferon Alfa-2b (36 Months) versus Low-Dose Interferon Alfa-2b (18 Months) in Melanoma Patients without Macrometastatic Nodes: An Open-Label, Randomised, Phase 3 European Association for Dermato-Oncology (EADO) Study. European Journal of Cancer, 49, 166174. https://doi.org/10.1016/j.ejca.2012.07.018

[5] McMasters, K.M., Egger, M.E., Edwards, M.J., et al. (2016) Final Results of the Sunbelt Melanoma Trial: A Multi-Institutional Prospective Randomized Phase III Study Evaluating the Role of Adjuvant High-Dose Interferon Alfa-2b and Completion Lymph Node Dissection for Patients Staged by Sentinel Lymph Node Biopsy. Journal of Clinical Oncology, 34, 10791086. https://doi.org/10.1200/JCO.2015.63.3776

[6] Eggermont, A.M., Chiarion-Sileni, V., Grob, J.J., et al. (2015) Adjuvant Ipilimumab versus Placebo after Complete Resection of High-Risk Stage III Melanoma (EORTC 18071): A Randomised, Double-Blind, Phase 3 Trial. The Lancet Oncology, 16, 522-530. https://doi.org/10.1016/S1470-2045(15)70122-1

[7] Albrecht, K.J., Nashan, D., Meiss, F., Bengel, J. and Reuter, K. (2014) Shared Decision Making in Dermato-Oncology: Preference for Involvement of Melanoma Patients. Melanoma Research, 24, 68-74. https://doi.org/10.1097/CMR.0000000000000030

[8] Schofield, P.E., Beeney, L.J., Thompson, J.F., Butow, P.N., Tattersall, M.H. and Dunn, S.M. (2001) Hearing the Bad News of a Cancer Diagnosis: The Australian Melanoma Patient's Perspective. Annals of Oncology, 12, 365-371. https://doi.org/10.1023/A:1011100524076

[9] Kilbridge, K.L., Weeks, J.C., Sober, A.J., et al. (2001) Patient Preferences for Adjuvant Interferon Alfa-2b Treatment. Journal of Clinical Oncology, 19, 812-823.

[10] Krammer, R. and Heinzerling, L. (2014) Therapy Preferences in Melanoma TreatmentWillingness to Pay and Preference of Quality versus Length of Life of Patients, Physicians and Healthy Controls. PLOS ONE, 9, e111237. https://doi.org/10.1371/journal.pone.0111237

[11] US Department of Health and Human Services, Food and Drug Administration, Center for Devices and Radiological Health and Center for Biologics Evaluation and Research (2016) Patient Preference Information-Voluntary Submission, Review in Premarket Approval Applications, Humanitarian Device Exemption Applications, and de Novo Requests, and Inclusion in Decision Summaries and Device Labeling. Guidance for Industry, Food and 
Drug Administration Staff, and Other Stakeholders.

http://www.fda.gov/downloads/MedicalDevices/DeviceRegulationandGuidance/GuidanceD ocuments/UCM446680.pdf

[12] Bridges, J.F.P., Kinter, E.T., Kidane, L., Heinzen, R.R. and McCormick, C. (2008) Things are Looking up since We Started Listening to Patients: Recent Trends in the Application of Conjoint Analysis in Health 1970-2007. Patient, 1, 273-282.

https://doi.org/10.2165/1312067-200801040-00009

[13] Bridges, J.F.P., Hauber, A.B., Marshall, D., et al. (2011) Conjoint Analysis Applications in Health-A Checklist: A Report of the ISPOR Good Research Practices for Conjoint Analysis Task Force. Value in Health, 14, 403-413. https://doi.org/10.1016/j.jval.2010.11.013

[14] Wong, S.F., Norman, R., Dunning, T.L., Ashley, D.M. and Lorgelly, P.K. (2014) A Protocol for a Discrete Choice Experiment: Understanding Preferences of Patients with Cancer towards Their Cancer Care Across Metropolitan and Rural Regions in Australia. BMJ Open, 4, e006661. https://doi.org/10.1136/bmjopen-2014-006661

[15] US Department of Health and Human Services, National Institutes of Health and National Cancer Institute (2009) Common Terminology Criteria for Adverse Events (CTCAE). Version 4.0.

http://evs.nci.nih.gov/ftp1/CTCAE/CTCAE_4.03_2010-06-14_QuickReference_5x7.pdf

[16] Kirkwood, J.M., Strawderman, M.H., Ernstoff, M.S., Smith, T.J., Borden, E.C. and Blum, R.H. (1996) Interferon Alfa-2b Adjuvant Therapy of High-Risk Resected Cutaneous Melanoma: The Eastern Cooperative Oncology Group Trial EST 1684. Journal of Clinical Oncology, 14, 7-17.

[17] Sylatron (Peginterferon Alfa-2b) Prescribing Information (2011) Schering Corporation, Kenilworth. http://www.accessdata.fda.gov/drugsatfda_docs/label/2011/103949s5153lbl.pdf

[18] Intron A (Interferon Alfa-2b) Prescribing Information (2016) Merck Sharp \& Dohme Corp, Whitehouse Station.

https://www.merck.com/product/usa/pi_circulars/i/intron_a/intron_a_pi.pdf

[19] Yervoy (Ipilimunab) Prescribing Information (2016) Bristol-Myers Squibb, Princeton. http://packageinserts.bms.com/pi/pi_yervoy.pdf

[20] Schadendorf, D., Hodi, F.S., Robert, C., et al. (2015) Pooled Analysis of Long-Term Survival Data from Phase II and Phase III Trials of Ipilimumab in Unresectable or Metastatic Melanoma. Journal of Clinical Oncology, 33, 1889-1894. https://doi.org/10.1200/JCO.2014.56.2736

[21] O’Donnell, H., Phillips, R.S., Wenger, N., Teno, J., Davis, R.B. and Hamel, M.B. (2003) Preferences for Cardiopulmonary Resuscitation among Patients 80 Years or Older: The Views of Patients and Their Physicians. Journal of the American Medical Directors Association, 4, 139-144. https://doi.org/10.1016/S1525-8610(04)70323-0

[22] Johnson, F.R., Lancsar, E., Marshall, D., et al. (2013) Constructing Experimental Designs for Discrete-Choice Experiments: Report of the ISPOR Conjoint Analysis Experimental Design Good Research Practices Task Force. ISPOR Task Force Report. Value in Health, 16, 3-13. https://doi.org/10.1016/j.jval.2012.08.2223

[23] Hauber, A.B., Fairchild, A.O. and Johnson, F.R. (2013) Quantifying Benefit-Risk Preferences for Medical Interventions: An Overview of a Growing Empirical Literature. Applied Health Economics and Health Policy, 11, 319-329. https://doi.org/10.1007/s40258-013-0028-y

[24] Hauber, A.B., González, J.M., Groothuis-Oudshoorn, C.G.M., et al. (2016) Statistical Methods for the Analysis of Discrete Choice Experiments: A Report of the ISPOR Conjoint Analysis Good Research Practices Task Force. Value in Health, 19, 300-315. https://doi.org/10.1016/j.jval.2016.04.004

[25] Hamelinck, V.C., Bastiaannet, E., Pieterse, A.H., et al. (2014) Patients' Preferences for Sur- 
gical and Adjuvant Systematic Treatment in Early Breast Cancer: A Systematic Review. Cancer Treatment Reviews, 40, 1005-1018. https://doi.org/10.1016/j.ctrv.2014.06.007

[26] Brundage, M.D., Davidson, J.R., Mackillop, W.J., Feldman-Stewart, D. and Groome, P. (1998) Using a Treatment-tradeoff Method to Elicit Preferences for the Treatment of Locally Advanced Non-Small-Cell Lung Cancer. Medical Decision Making, 18, 256-267. https://doi.org/10.1177/0272989X9801800302

[27] Chandwani, S., Stevinson, K.L. and Mehnert, J.M. (2014) Predictors of Receipt of Immunotherapy for Stage II and III Melanoma in United States Clinical Practice. Journal of Clinical Oncology, 32, e20003.

[28] Eggermont, A.M., Chiarion-Sileni, V., Grob, J.J., et al. (2016) Prolonged Survival in Stage III Melanoma with Ipilimumab Adjuvant Therapy. New England Journal of Medicine, 375, 1845-1855. https://doi.org/10.1056/NEJMoa1611299

Submit or recommend next manuscript to SCIRP and we will provide best service for you:

Accepting pre-submission inquiries through Email, Facebook, LinkedIn, Twitter, etc. A wide selection of journals (inclusive of 9 subjects, more than 200 journals)

Providing 24-hour high-quality service

User-friendly online submission system

Fair and swift peer-review system

Efficient typesetting and proofreading procedure

Display of the result of downloads and visits, as well as the number of cited articles

Maximum dissemination of your research work

Submit your manuscript at: http://papersubmission.scirp.org/

Or contact jct@scirp.org 